http://jmscr.igmpublication.org/home/ ISSN (e)-2347-176x ISSN (p) 2455-0450

crossref DOI: https://dx.doi.org/10.18535/jmscr/v7i11.50

\title{
Correlation of Central Corneal Thickness with Type 2 Diabetes Mellitus
}

Authors

\section{Prof Dr Prasanta Kumar Nanda, Dr Antarlin Ghosal}

\section{Introduction}

- Diabetes Mellitus is one of the most common causes of systemic as well as ocular morbidity in older age group.

- Glaucoma is also another important ocular disease mainly affecting older age group.

- To screen any diabetic patient for glaucoma, CENTRAL CORNEAL THICKNESS (CCT) is an important factor to be taken into account as it can directly affect the disease progression as well as it can separately alter the IOP value.

- Diabetes Mellitus can affect the corneal endothelium by altering the function of Na-K ATPase pump activity, thus causing alteration of corneal morphology and can cause increase in central corneal thickness (CCT) also.

\section{Aim of the Study}

- The aim of this study is to determine if there is any correlation between-
1) The CCT with the diabetes.

2) The CCT with the severity of the disease process measured as the staging of diabetic retinopathy.

\section{Method}

- A cross-sectional study was done in RIO, Cuttack during October 2017- March 2019.

- Total 124 controls were taken along with 124 cases with Type2 Diabetes Mellitus who came to the OPD for routine fundoscopy.

- After performing fundoscopy, the cases were divided into 3 parts-

$>$ Subgroup 1 (no DR changes)- 46 cases

$>$ Subgroup 2 (NPDR)- 64 cases

$>$ Subgroup 3 (PDR)- 14 cases

- Central Corneal Thickness was then measured with optical pachymeter and recorded.

\begin{tabular}{|c|c|}
\hline Inclusion Criteria & Exclusion Criteria \\
\hline Age $>40$ years & Refractive error $>2 \mathrm{D}$ \\
\hline $\begin{array}{c}\text { Type } 2 \mathrm{DM} \text { already diagnosed before by a } \\
\text { physician }\end{array}$ & $\begin{array}{c}\text { Presence of glaucoma or any co- } \\
\text { morbidity }\end{array}$ \\
\hline $\begin{array}{c}\mathrm{HbA} 1 \mathrm{c}<7 \% \text { documented within } 1 \text { month of } \\
\text { the study }\end{array}$ & H/O any ocular surgery \\
\hline
\end{tabular}




\section{Results}

- The mean CCT of the control group was 528 um.

- The mean CCT of the study group was found to be 549 um.
- Moreover, the Subgroup 3 showed higher CCT (566 um) as compared to Subgroup 2 (552 um) and Subgroup 1 (541um).
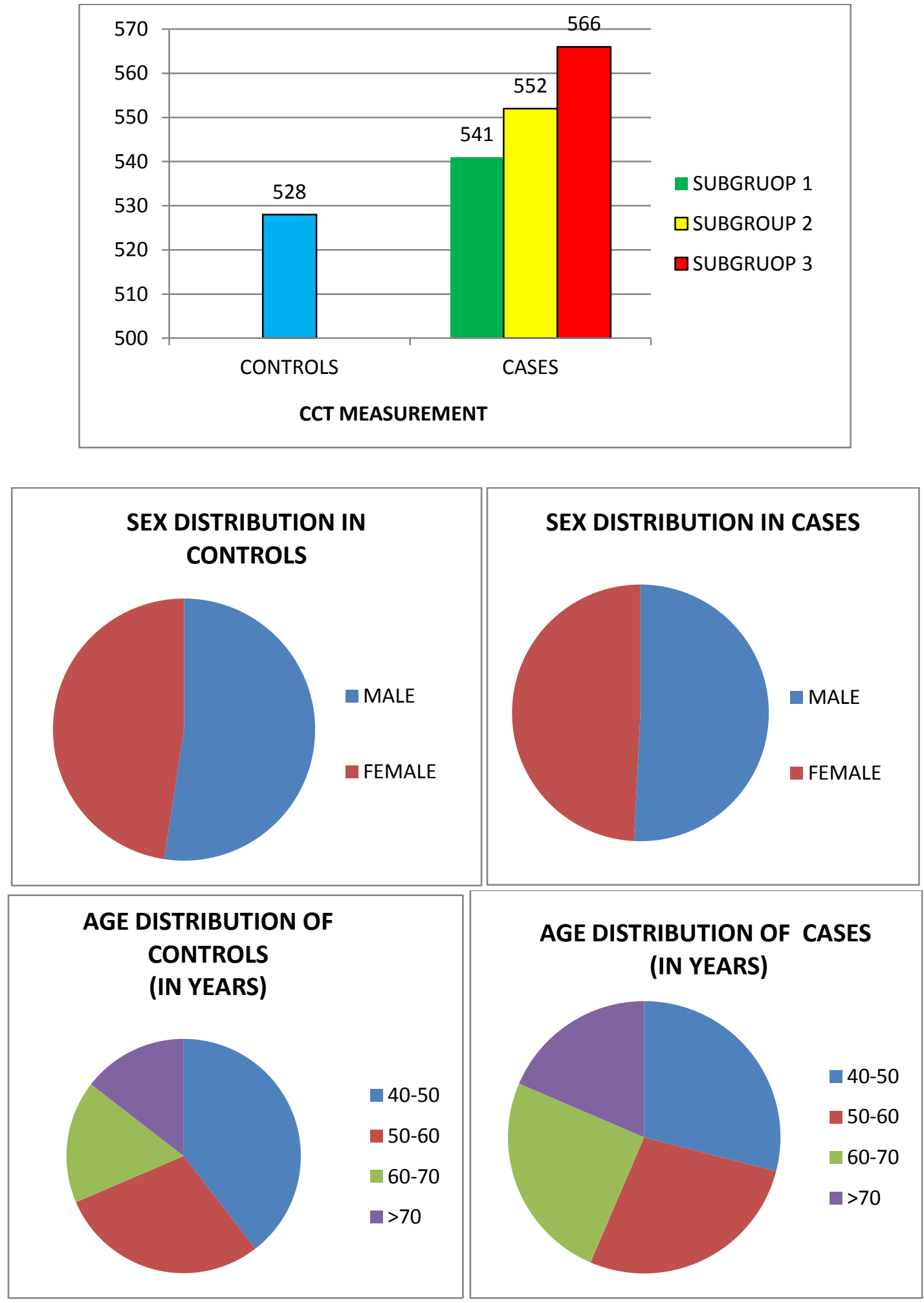

However, the age and sex distribution of the controls and cases re found to be similar 


\section{Statistical Data}

- Chi-square test was applied to compare the results

- Sample mean- 549.5 um

- Standard deviation- 11.3 um

- P value - 0.1 (subgroup 1), 0.01 (subgroup 2), 0.0001 (subgroup 3)

\section{Conclusion}

- Thus we can see that the CCT of diabetics are higher than non-diabetic individuals.

- The increased CCT in both NPDR and PDR has statistical significance ( $p$ value $<0.05$ )

- This higher CCT can overestimate the IOP reading in tonometry raising a false suspicion of glaucoma. So, performing a CCT measurement can be advised along with it.

- The higher CCT may also fail to predict the risk of developing glaucoma in those individuals.

- CCT can also help in identification of those individuals with T2 DM who could be of higher risk of developing severe systemic and ocular complications later.

\section{References}

1. Ozdamar Y et al, 2010- CCT of diabetics are more as compared to normal population.

2. Sorokhaibam R et al, 2015- reported increase in CCT in diabetics

3. N Mcnamara et al- stated that CCT changes are due to hyperglycemic effect on cornea which inhibits the endothelial pump.

4. Sumita Sethy et al, july 2017-reported that diabetics have significant increase in CCT as compared to normal individuals. 